\title{
CRIAÇÃO DO GABINETE DE FISIOTERAPIA DO CORPO DE BOMBEIROS MILITAR DE PERNAMBUCO E ANÁLISE DOS ATENDIMENTOS
}

\section{RESUMO}

O Corpo de Bombeiros Militar do Estado de Pernambuco iniciou em 2017 os atendimentos no seu Gabinete de Fisioterapia. O presente artigo tem como objetivo apresentar a criação deste Gabinete de Fisioterapia e a análise dos atendimentos realizados durante seus primeiros anos de funcionamento. Antes de cada atendimento, propriamente dito, foi aplicado em todos os pacientes um questionário para se conhecer o perfil do público atendido e as características de cada patologia. Em seguida os dados foram analisados, lançados em planilha e foi feita uma estatística de quantidade e tipo de lesão por região corporal, pela qual foi possível conhecer as lesões que mais afetaram os bombeiros. Concluímos, de acordo com os resultados, a considerável importância da Fisioterapia no trabalho desses profissionais através dos quais se verificou que 0 acompanhamento não pode ser apenas durante 0 tratamento, mas também na prevenção de todo o processo que norteia as atividades do bombeiro

Palavras-chave: Bombeiro; Risco; Sobrecarga.

\footnotetext{
1 Sargento do Corpo de Bombeiros Militar de Pernambuco, graduado em Fisioterapia pela FAREC-Faculdade do Recife (2015), Pós-Graduado em Fisioterapia Esportiva pela UNINTERCentro Universitário Internacional (2016). Email: samuelluz@ hotmail.com
} 


\title{
THE ESTABLISHMENT OF THE PHYSIOTHERAPY CABINET OF THE MILITARY FIREFIGHTER OF THE STATE OF PERNAMBUCO AND THE ANALYSIS OF ITS SERVICES
}

\begin{abstract}
The Military Fire Brigade of the State of Pernambuco began the services at its Physiotherapy cabinet in 2017. The objective of this article is to submit the establishment of the Physiotherapy office and the analysis of the services provided during its first years of operation. Previously to each service a survey was applied to the patients with a view to check and know the profile of the public taken and the characteristics of each disease. So the data were studied, sent in a spreadsheet and a statistic of the quantity and kind of injury was done by body region; then it was possible to know the injuries that most affected the firefighters. We came to the conclusion, based on the results, about the considerable importance of Physiotherapy in the rehabilitation work of these professionals and through that it was verified that the following-up mustn't be done during the treatment only, but in the prevention of all the processes related to the firefighters' practices as well.
\end{abstract}

Keywords: Firefighter; Risk; Overload.

Artigo Recebido em 09/09/2018 - Aceito em 01/03/2019 - Publicado em 31/03/2019 


\section{INTRODUÇÃO}

O Comandante Geral do Corpo de Bombeiros Militar do estado de Pernambuco (CBMPE), Cel. BM Manoel Francisco de Oliveira Cunha Filho, no dia 23 de dezembro de 2016, através da Portaria do Comando Geral no 078/16CAS, de 22/12/2016, publicada no Boletim Geral Eletrônico, BGE no 239/2016 de 23/12/2016, inaugurou o Gabinete de Fisioterapia do CAS/CBMPE, localizado no Centro de Assistência Social - CAS (foto 01), em prédio anexo, em frente ao Quartel do Comando Geral do CBMPE, situado na AV. João de Barros, bairro da Boa Vista-Recife, (foto 01) onde já havia atendimento odontológico e psicológico, entre outros benefícios, agora os bombeiros militares contam com mais esse novo recurso, fundamental para reabilitação fisioterápica dos seus militares.

Foto 01-Fachada do Centro de Assistência Social - CAS/CBMPE

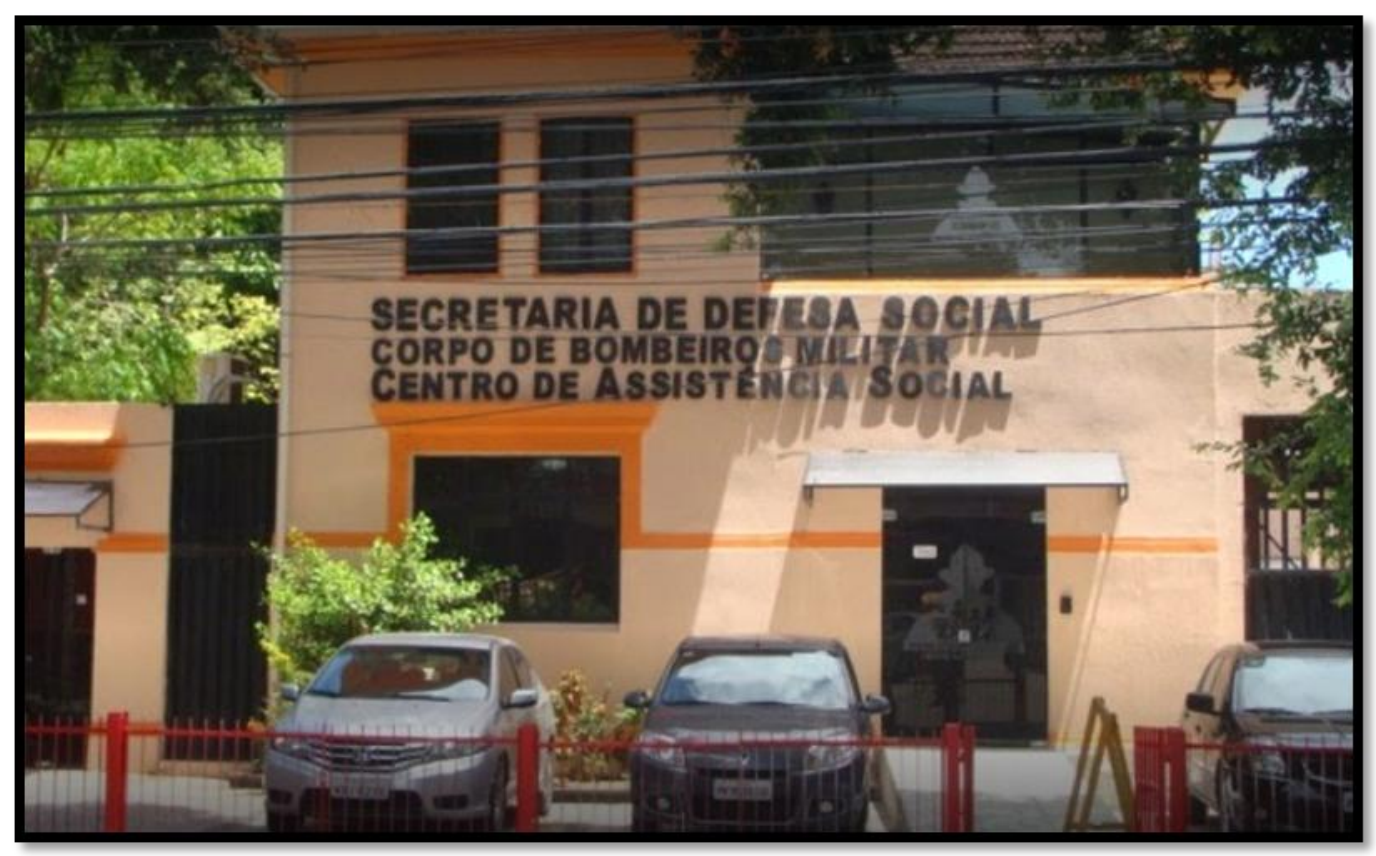

O Gabinete de Fisioterapia conta com um espaço bem equipado correspondente a uma área de cerca de 25 metros quadrados (foto 02). Tendo como foco os atendimentos na especialidade de traumato ortopedia, que atua na prevenção e no tratamento de distúrbios do sistema musculoesqueletico, sejam eles crônicos ou agudos. 
Revista Científica do Corpo de Bombeiros Militar de Pernambuco

Artigo publicado no Vol.05 Nº12 - Edição de JAN a JUN 2019 - ISSN 2359-4829

Versão on-line disponível em: http://www.revistaflammae.com.

Foto 02.- Espaço físico do Gabinete de Fisioterapia do CAS/CBMPE

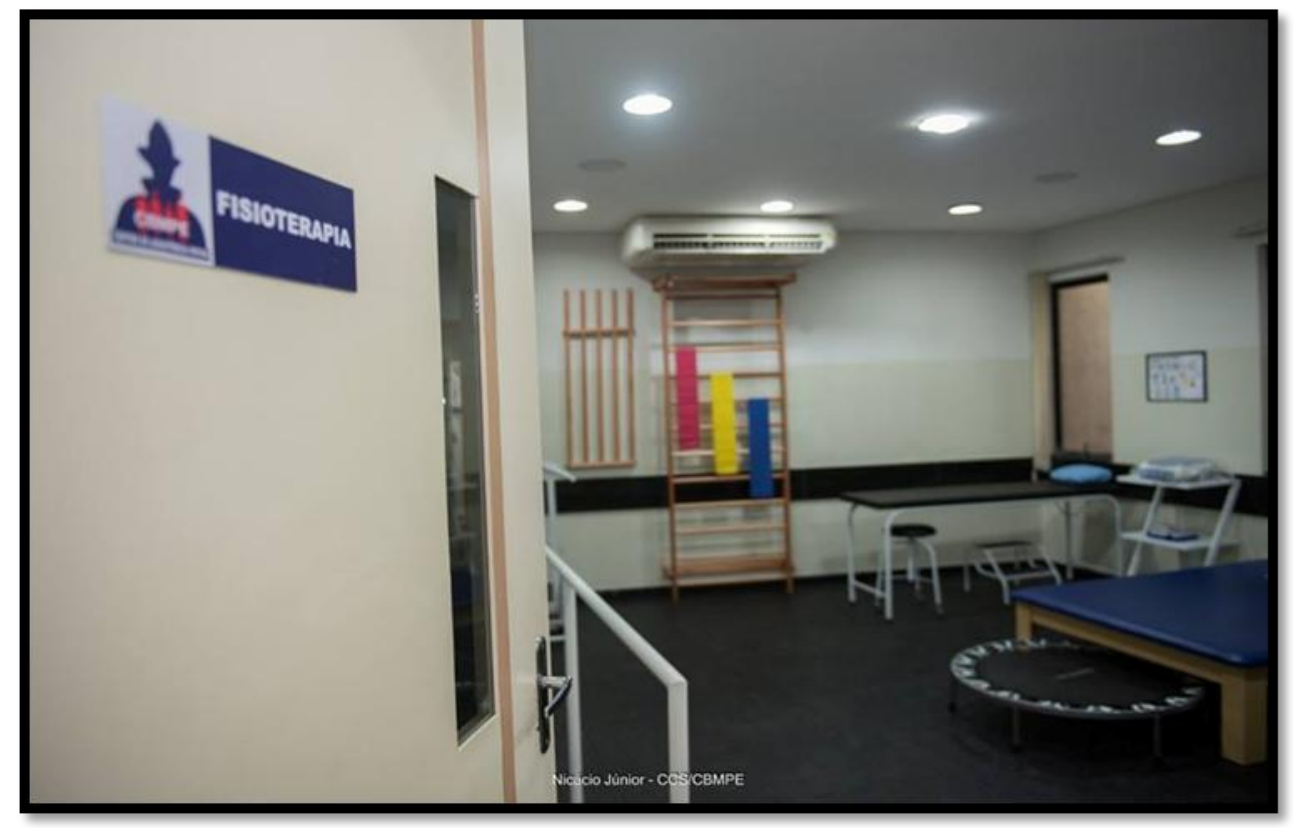

A atividade exercida pelos bombeiros, salvando vidas de terceiros e para defender bens públicos e privados da sociedade, configura-se uma profissão que expõe o trabalhador a inúmeros riscos. (NATIVIDADE, 2009).

Além dos riscos físicos como, quedas, fraturas, cortes, torções, e outras lesões, há também o comprometimento emocional durante a atividade operacional fazendo com que esse profissional transfira toda a sua energia vital em prol do bem-estar do outro, e assim, na menor possibilidade de erro, vidas estão em risco, tanto do bombeiro quanto da vítima (PRADO, 2011).

A sobrecarga física dos bombeiros deve-se as atividades específicas por eles desempenhadas, entre elas: serviços de prevenção e de extinção de incêndio, resgate, busca e salvamento, atendimento pré-hospitalar, resgate com embarcações, vistorias, entre outras atribuições que competem ao Corpo de Bombeiro Militar de Pernambuco. (ALEPE, 2013). 


\section{OBJETIVOS}

O pressente artigo tem como objetivo apresentar a criação do Gabinete de Fisioterapia do CBMPE e a análise dos atendimentos realizados durante seus primeiros anos de funcionamento que contemplaram o atendimento dos bombeiros militares e seus dependentes, mostrando o quantitativo destes, 0 perfil do público atendido e os tipos de lesões que estiveram sendo tratadas no local durante determinado período de tempo.

O artigo também tem o objetivo de fazer a exposição dos diversos tipos de trabalhos realizados pelo Gabinete de fisioterapia, onde além de atendimentos pós-cirúrgicos diversos, como nas reabilitações depois de cirurgias de fraturas ou rupturas de ligamentos e também nos processos préoperatórios, onde é feita a redução do processo inflamatório e o fortalecimento muscular antes do bombeiro se submeter ao processo cirúrgico, bem como, na chamada atenção primária à saúde, que consiste na orientação do bombeiro militar como forma preventiva.

\section{MÉTODOS}

A fim de desenvolver o presente trabalho descritivo e quantitativo, antes de iniciar o tratamento do bombeiro, foi realizada a chamada anamnese, onde um questionário padrão é aplicado no paciente para saber os detalhes sobre a sua patologia e se conhecer o perfil do público atendido. Nesta avaliação os pacientes relatam além de dados pessoais como nome, idade, atividade realizada no desempenho da função, etc; também é registrado o histórico de como iniciaram os sintomas da lesão, se através de trauma direto como uma queda, ou os sintomas foram aparecendo e aumentando ao longo do tempo.

Também faz parte do questionário perguntar se o bombeiro é portador de alguma patologia como, hipertensão arterial, diabetes, existência de placas/parafusos em alguma parte do corpo, entre outras indagações 
relevantes para o tratamento, são realizados também testes motores específicos para avaliar o quadro do paciente.

De posse destes questionários, ao final do ano, são lançados todos os dados em planilhas de Excel e analisadas as estatísticas de quais tipos de lesões foram as mais freqüentes, em qual região corporal e qual o perfil do público atendido, sendo confeccionado uma relatório anual para que fiquem registrados todos os dados coletados.

\section{RESULTADOS}

\subsection{TIPOS DE LESÕES.}

As lesões mais atendidas em 2017 foram as localizadas no complexo articular do joelho, sendo algumas delas: rupturas totais e parciais de ligamentos, principalmente o Ligamento Cruzado Anterior (LCA) e o Ligamento Colateral Medial (LCM), desgaste de cartilagem (condropatias), ruptura de menisco e inflamação de tendões.

As lesões do complexo articular do ombro se destacaram como o segundo tipo de patologia que mais foram tratadas no gabinete de fisioterapia, sendo causadas tanto por trauma direto, como por sobrecarga a longo prazo.

As patologias envolvendo a coluna vertebral ficaram em terceiro lugar em quantidade de sessões realizadas, lombar, cervical e torácica, respectivamente nessa sequência.

Outras lesões muito atendidas também foram as tendinopatias (inflamação nos tendões) do punho, cotovelo, torção de tornozelos, rupturas de tendões e fraturas de membros superiores e inferiores.

\subsection{QUANTIDADE DE ATENDIMENTOS}

A quantidade de sessões de fisioterapia realizadas nos bombeiros em 2017 ultrapassou o número de dois mil atendimentos, com destaque para as intervenções realizadas no complexo articular do joelho (520), sessões feitas nos ombros (415), e intervenções para reabilitação de patologias da coluna (322), seguidos de tendinites no punho, e outras patologias. 


\section{Revista FLAMMAE}

Revista Científica do Corpo de Bombeiros Militar de Pernambuco

Artigo publicado no Vol.05 Nº12 - Edição de JAN a JUN 2019 - ISSN 2359-4829

Versão on-line disponível em: http://www.revistaflammae.com.

No gráfico 01 , podem ser visualizadas as quantidades de sessões realizadas durante o ano de 2017, com as respectivas regiões do corpo onde se encontravam as patologias.

Onde se lê atendimentos emergenciais, são aqueles que tem uma certa prioridade, caracterizados por episódios agudos de dor em membros superiores, inferiores ou coluna vertebral, de origem ocupacional, com incapacidade funcional grave para as atividades de vida diária ou trabalho.

Gráfico 01- Quantidade de sessões realizadas por região corporal em 2017.

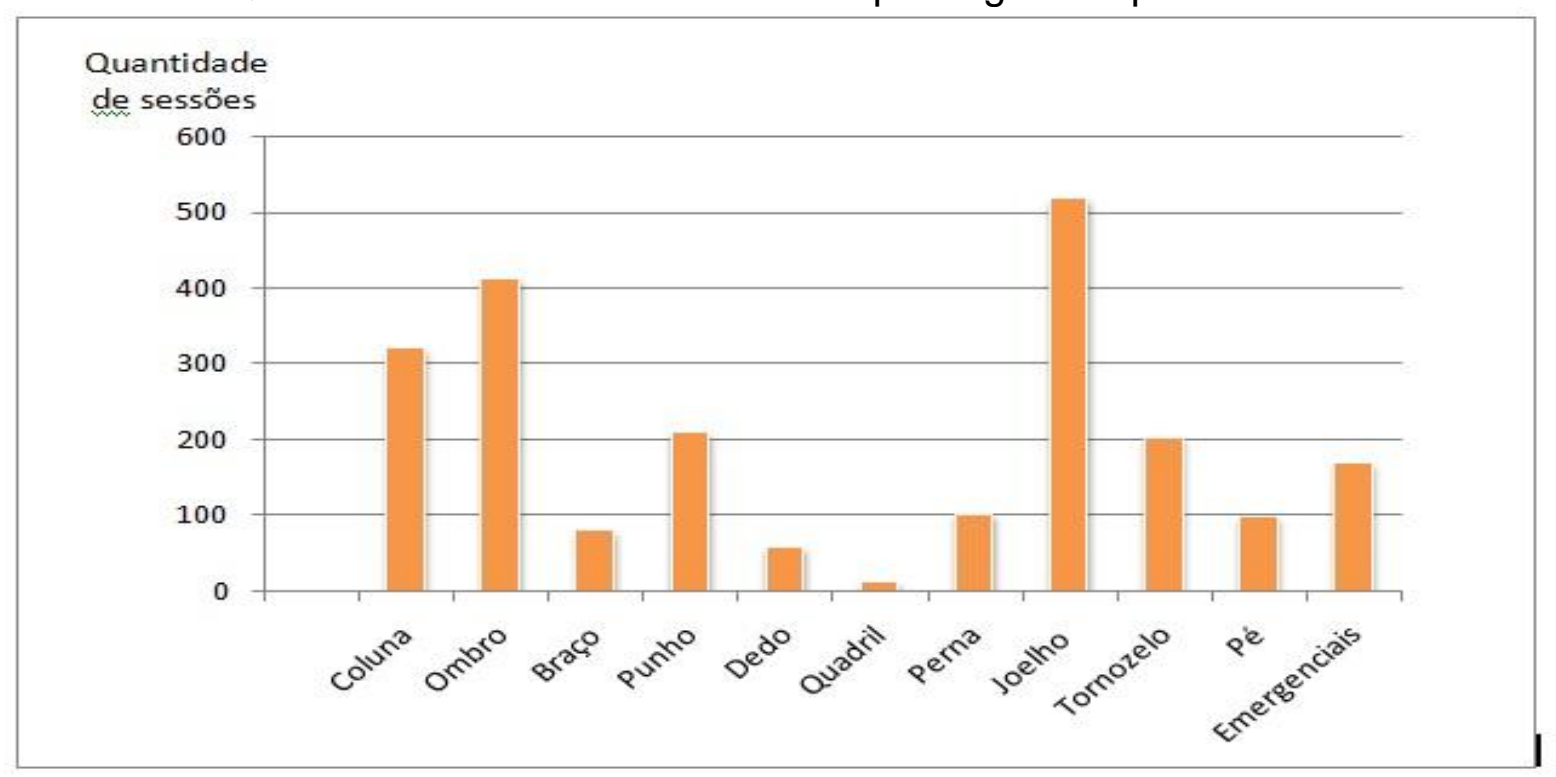

O gráfico 2, mostra os atendimentos realizados no ano de 2018, onde se percebe que houve um aumento considerado nas sessões realizadas.Gráfico 2. 
Revista Científica do Corpo de Bombeiros Militar de Pernambuco

Artigo publicado no Vol.05 Nº12 - Edição de JAN a JUN 2019 - ISSN 2359-4829

Versão on-line disponível em: http://www.revistaflammae.com.

Gráfico 2 - Quantidade de atendimentos no ano de 2018.

\section{Quantidade de sessóes por patologia}

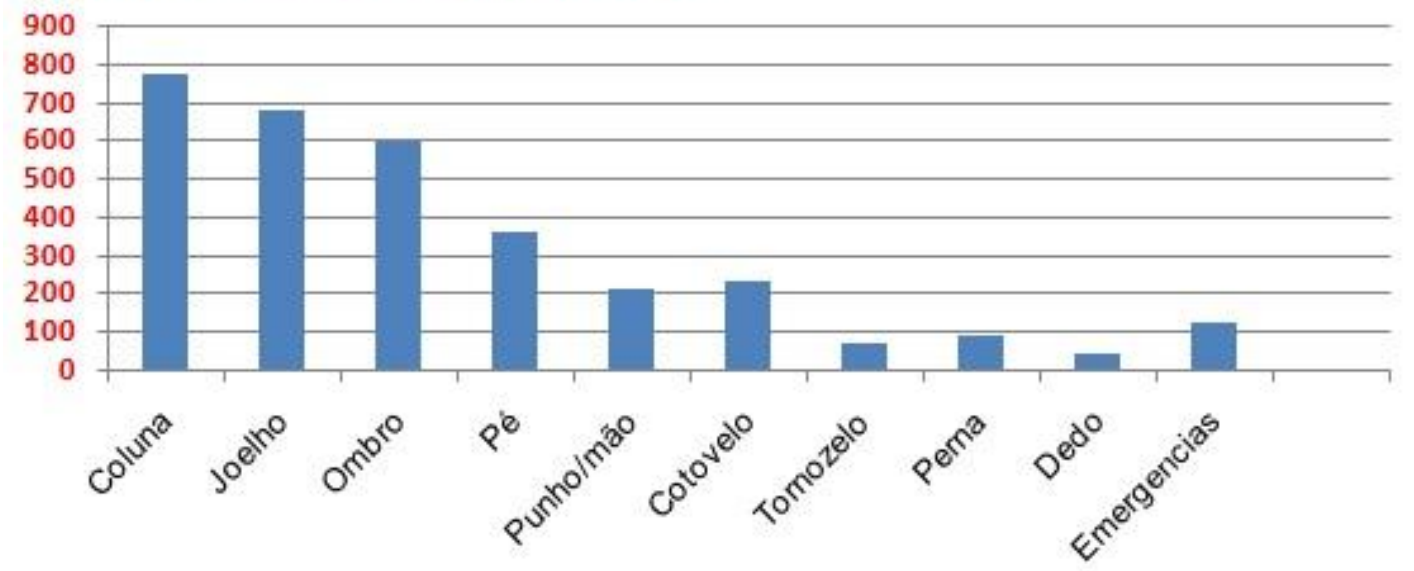

A tabela 01 mostra o comparativo dos atendimentos realizados nos dois primeiros anos de funcionamento do Gabinete de Fisioterapia do CAS/CBMPE, verificando-se um aumento de $31 \%$ na quantidade total de sessões realizadas. Devendo-se levar em consideração que, uma maior divulgação dos serviços foi um fator importante deste aumento. Outro fato que pode ser visualizado no gráfico do ano de 2018 , foi o grande aumento da procura por atendimentos relacionados a patologias localizadas na região da coluna vertebral.

Tabela 1-Comparativo dos atendimentos nos anos de 2017 e 2018.

\begin{tabular}{lll}
\hline Local da Patologia & Sessões em 2017 & Sessões em 2018 \\
Coluna & 322 & 780 \\
Joelho & 520 & 680 \\
Ombro & 415 & 600 \\
Pé & 99 & 360 \\
Punho/mão & 210 & 210 \\
Cotovelo/braço & 81 & 235 \\
Tornozelo & 204 & 65 \\
Perna & 103 & 90 \\
Dedo & 60 & 40 \\
Quadril & 13 & 00 \\
Emergenciais & 170 & 120 \\
Total & 2.197 & 3.180
\end{tabular}




\subsection{PERFIL DO PÚBLICO ATENDIDO}

A seguir, o gráfico 03 apresenta o público que foi atendido no Gabinete de Fisioterapia do CAS/CBMPE, sendo $80 \%$ do total de usuários composto pelos próprios bombeiros e $20 \%$ representam os dependentes destes militares.

Gráfico 03. Perfil do público atendido no Gabinete de Fisioterapia do CAS/CBMPE - Bombeiros e dependentes.

\section{Público atendido}

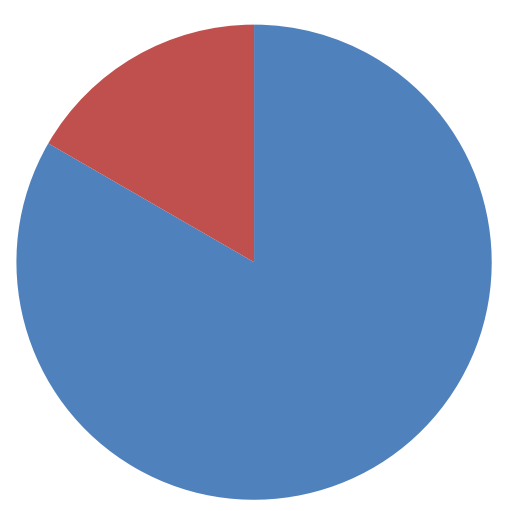

Bombeiros

- Dependentes

\section{DISCURSÃO}

Cada paciente foi submetido a sessões de fisioterapia com duração de 40 a 60 minutos, a quantidade total de sessões realizadas por paciente ficou em média 10 a 20 sessões em horários e dias pré-definidos, sendo limitada a quantidade de dois pacientes por cada horário, com o objetivo do fisioterapeuta poder dar total atenção aos bombeiros que estavam sendo atendidos, prestando um serviço diferenciado e de qualidade contribuindo para o seu restabelecimento o mais breve possível, e consequentemente à volta para as atividades de bombeiro tanto operacionais quanto administrativas.

Os atendimentos ambulatoriais dizem respeito aos realizados após 0 encaminhamento de um médico traumato-ortopedista, representando $92 \%$ do 
total de atendimentos, não necessitando tal requisição, ser emitida exclusivamente pelo Centro Médico Hospitalar da Polícia Militar de Pernambuco (Hospital em que todos os bombeiros militares são conveniados), mas podendo ser emitida de qualquer unidade de saúde tanto pública como privada, com o intuito de diminuir a burocracia, facilitando o acesso ao atendimento fisioterápico, e iniciando o mesmo no menor tempo possível, onde até o presente momento, não houve a necessidade de uma grande espera por uma vaga, sendo a rotatividade no processo de alta e a captação de novos pacientes muito rápida.

Os atendimentos chamados emergenciais ou prioritários, que somaram $8 \%$ do total de atendimentos, são aqueles que requerem certa urgência quando ocorrem e podem ser resolvidos ou minimizados, na maioria das vezes, com apenas uma sessão, podendo citar como exemplo, torcicolos, contraturas e estiramentos musculares, fazendo-se uso dos vários recursos da fisioterapia, onde o militar ao chegar no gabinete de fisioterapia e receber o atendimento, relatou uma melhora imediata e significativa.

Os tipos de recursos fisioterapêuticos que dispõe o Gabinete de Fisioterapia do CBMPE e utilizados nos bombeiros de Pernambuco, são: aparelhos de eletroterapia: TENS(eletro estimulador transcutâneo), Ultra Som e Laserterapia, usados para diminuição de edema, inflamação e dor, equipamentos para fortalecimento muscular como: alteres, caneleiras, faixa elástica, equipamentos para liberação miofascial, cama elástica e discos de propriocepção para exercícios de equilibrio, macas, rampa e escada com barras paralelas para o treino de marcha entre outros equipamentos, como pode ser visualizado alguns deles na foto 3 . 


\section{Revista FLAMMAE}

Revista Científica do Corpo de Bombeiros Militar de Pernambuco

Artigo publicado no Vol.05 º12 - Edição de JAN a JUN 2019 - ISSN 2359-4829

Versão on-line disponível em: http://www.revistaflammae.com.

Foto 3 - Visualização da estrutura com alguns materiais e equipamentos

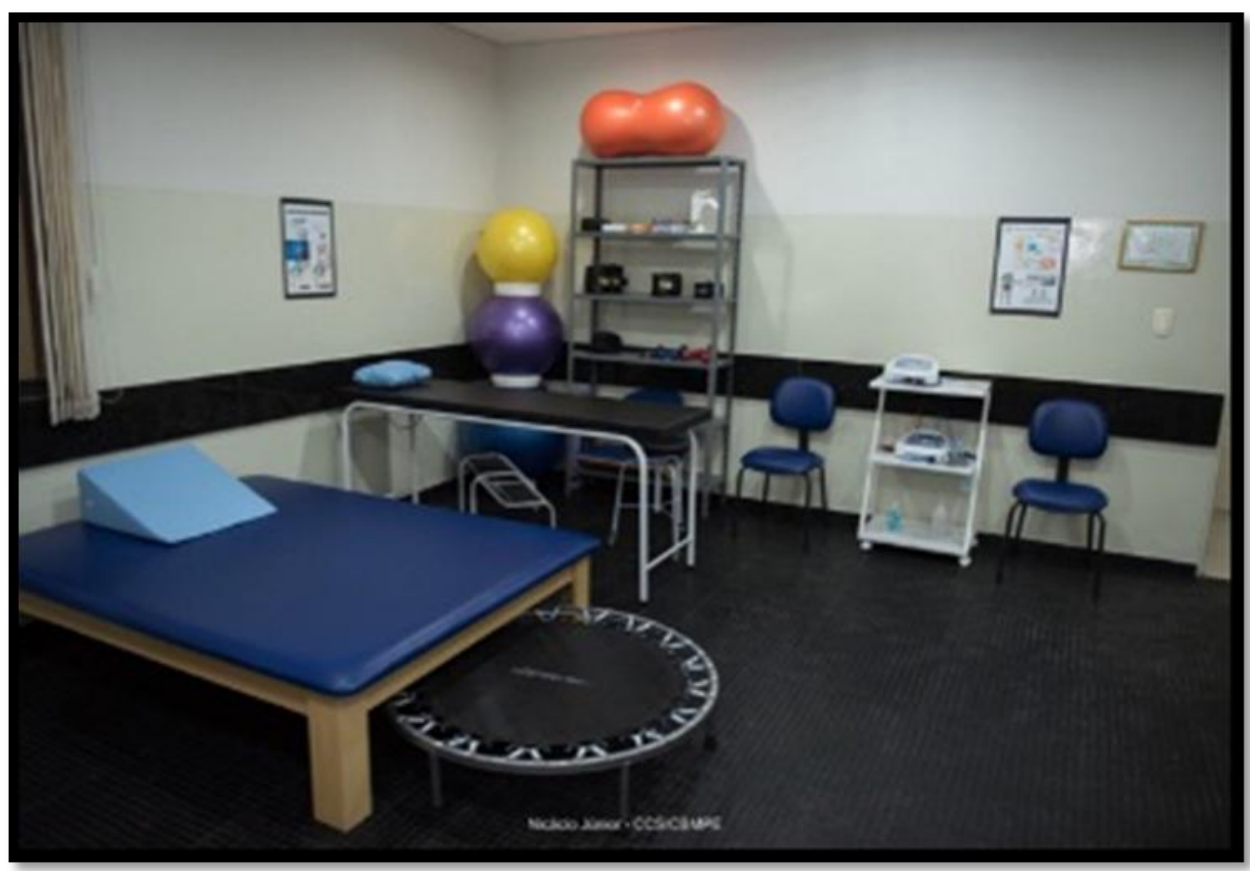

Também é aplicada no local bandagem elástica (técnica muito usada em atletas) e foi implantado também o uso de ventosaterapia e agulhamento seco no ano de 2018, representando uma melhora significativa nos sintomas dos pacientes com o uso desses novos recursos. (Foto 4).

Foto 4 - Bandagem elástica, Ventosa e Agulhamento Seco.
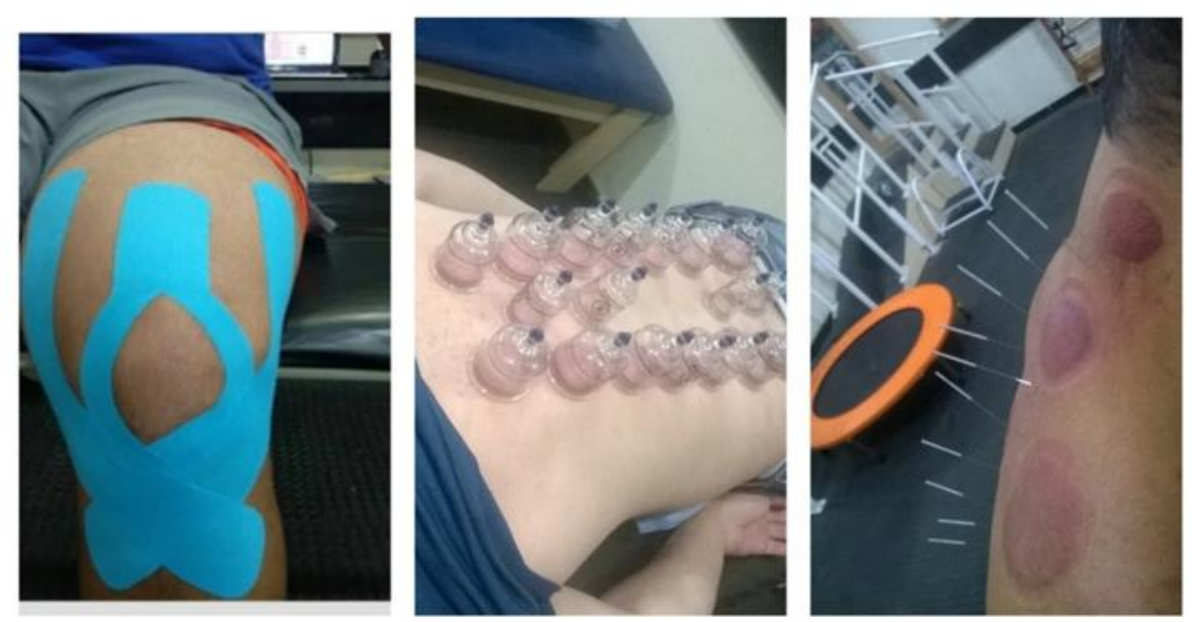
Foi observado durante a anamnese, segundo relatos dos pacientes, que as lesões atendidas são de causas heterogêneas, podendo ser citadas algumas em que se observou uma prevalência maior, como exemplo, lesões envolvendo prática esportiva, acidente de trânsito, vícios de postura, bem como causas laborais.

A etiologia das lesões nem sempre tem um histórico de trauma direto, muitas vezes são decorrentes de atividades realizadas ao longo do tempo, onde o indivíduo não se preocupa com fatores como a intensidade, a frequência e a sobrecarga durante os serviços executados, levando o mesmo a desencadear a longo prazo, as chamadas LER (lesões de esforço repetitivo) e DORT (Disturbio Osteomuscular Relacionado ao Trabalho).

Foi observado durante 0 atendimento de vários pacientes, 0 encurtamento de cadeias musculares anteriores (principalmente íliopsoas e quadríceps) e da cadeia posterior de membros inferiores, inferindo falta de alongamento freqüente e adequado de muitos bombeiros.

O sobrepeso também é uma das causas muito observadas que agravam a situação do paciente; em um estudo realizado no Corpo de Bombeiros de Pelotas-RS, avaliou-se o risco de sobrepeso e obesidade em soldados do corpo de bombeiros, o estudo objetivou avaliar o risco de obesidade e obesidade visceral de soldados do Corpo de Bombeiros de Pelotas-RS, onde, concluiu-se que os resultados indicaram que uma parte considerável do batalhão $(29,8 \%)$ encontrava-se na zona de sobrepeso e mais expostos aos riscos relacionados ao excesso de gordura corporal (CANABARRO et al, 2010).

Há que se considerar a importância da Fisioterapia do Trabalho, para acompanhamento de todo processo que norteia as atividades do bombeiro. Ao conhecer seu trabalho, a intervenção pode ser eficaz a fim de evitar os problemas dele decorrentes, uma vez que a atuação dessa área se caracteriza pelo exercício profissional em todos os níveis de atenção à saúde sob um 
enfoque multidisciplinar, com o propósito de melhorar a qualidade de vida e o desempenho do trabalhador. (VIDOTTI, et al, 2015).

\section{CONCLUSÃO}

Foram observados como fundamentais no processo de prevenção das lesões, o fortalecimento e alongamento das musculaturas de membros inferiores para prevenir lesões como as dos ligamentos do joelho e entorses de tornozelo, contraturas e estiramentos e dos membros superiores, inclusive do complexo articular do ombro (manguito rotador), uma vez que foram constatadas muitas lesões nesta região e fortalecimento dos músculos que promovem a proteção da coluna vertebral em virtude do aumento destas solicitações.

De acordo com a quantidade e tipos de lesões atendidas, fica evidenciada a importância dos serviços de fisioterapia para a reabilitação dos bombeiros, bem como a necessidade de um trabalho preventivo com palestras, trabalho de ginástica laboral, de fortalecimento e condicionamento físico para se ter um melhor conhecimento ergonômico por parte do bombeiro militar, para que se tenha cada vez mais a disciplina e a consciência corporal para atitudes como, levantar um peso, se abaixar e até mesmo no uso de EPI, esses são apenas alguns cuidados que não se pode negligenciar, pois o bombeiro exerce uma atividade onde é fundamental estar sempre orientado, visando a prevenir lesões.

\section{REFERÊNCIAS}

CANABARRO, Lúcio K, ROMBALDI, Airton J. Risco de sobrepeso e obesidade em soldados do corpo de bombeiros, 2010. Disponível em: $<$ http://bases.bireme.br/cgibin/wxislind.exe/iah/online/? IsisScript=iah/iah.xis\&src=google\&base=LILACS\&la ng=p\&nextAction=Ink\&exprSearch=574531\&indexSearch=|D>, acesso em, 10 ago. 2018. 
NATIVIDADE, Michelle Regina da. Vidas em risco: a identidade profissional dos bombeiros militares, 2009 Disponível em, http://www.scielo.br/scielo.php?pid=S0102-

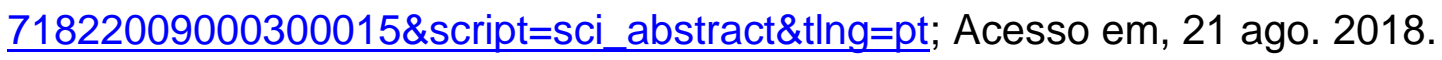

PERNAMBUCO (estado) Assembléia Legislativa-ALEPE, lei № 15.187, de 12 de dezembro de 2013, dispõe sobre organização básica do Corpo de Bombeiros, Art. $2^{\circ}$ competências.

PRADO, J.S. Estresse e qualidade de vida de Bombeiros Militares. 2011.

79f. Dissertação [Mestrado em Psicologia] - Faculdade de Psicologia, Universidade Católica Dom Bosco. Campo Grande - MS, 2011.

VIDOTTI, H. et al; Qualidade de vida e capacidade para o trabalho de bombeiros. $2015 . \quad$ Disponível em, http://www.scielo.br/scielo.php?pid=S1809$29502015000300231 \&$ script=sci abstract\&tlng=pt 